\title{
ARTICLE
}

\section{Po-210 distribution image and radioactivity determination in inner organ of fish with nuclear track detector CR-39}

\author{
Chizuo Mori* \\ Department of Applied Chemistry, Aichi Institute of Technology, 1247 Yachigusa, Yagusa-cho, Toyota-shi, Aichi Pref., \\ 470-0392, Japan
}

\begin{abstract}
The distribution images of $\alpha$-emission nuclides in the inner organ of dried sea fish such as sardine were obtained with nuclear track detector CR-39 by exposing for about 3 months. To obtain the radioactivity density in the inner organ from the pit density on the surface of CR-39, the detection efficiency of $\alpha$-particle emitted in the organ was obtained by the calculation of energy loss of $\alpha$-particles in the organ and in CR-39 using Bethe formula. The radioactivity densities were $1.3 \mathrm{~Bq} / \mathrm{cm}^{3}$ and $85 \mathrm{~Bq} / \mathrm{cm}^{3}$ for sardine and the liver of golden threadfin bream, respectively, and the energy absorption doses were $33 \mathrm{mGy} / \mathrm{y}$ and $2.2 \mathrm{~Gy} / \mathrm{y}$, respectively.
\end{abstract}

Keywords: sea fish; inner organ; a-emitter; distribution image; CR-39; energy loss; detection efficiency; pit density; radioactivity; absorption dose

\section{Introduction}

Because of the ingestion intake of $\alpha$-nuclides in fish, Japanese internal dose is rather high $0.8 \mathrm{mS} / \mathrm{y}$ in the total of $2.1 \mathrm{mSv} / \mathrm{y}$ [1]. The content of $\alpha$-nuclide in dried sardine is reported to be about $300 \mathrm{~Bq} / \mathrm{kg}$ [2]. Inner organ of fish contains fairly large amount of ${ }^{210} \mathrm{Po}[3,4]$. ${ }^{210} \mathrm{Po}$ is considered to be the most important contributor to the radiation dose received by humans via fish consumption [5,6]. Fish ingest ${ }^{210} \mathrm{~Pb}$ and its decay product ${ }^{210} \mathrm{Po}$ through food chain from plankton in sea water. The contents of ${ }^{210} \mathrm{~Pb}$ with long half-life (22.3 y, $\beta$-emitter) and ${ }^{210} \mathrm{Po}$ with short half-life (138.4 day, $\alpha$-emitter) in sea water are large [7]. However, because of the intake characteristics of plankton and the food chain, radioactive equilibrium is generally not maintained in fish body [8].

The analytical method of ${ }^{210} \mathrm{Po}$ adopted in the references [9] is generally sophisticated as follows: wet digestion of fish $\rightarrow$ deposition $\rightarrow \rightarrow$ dissolution $\rightarrow \rightarrow$ addition of ${ }^{209} \mathrm{Po}$ as yield tracer $\rightarrow \rightarrow$ elution through resin-column (or $\rightarrow$ - electroplating on a metal surface) $\rightarrow \rightarrow$ measurement with scintillation counter (or with Si-detector).

Although there are many reports on the radioactivity density and the ratio of ${ }^{210} \mathrm{Po} /{ }^{210} \mathrm{~Pb}$, papers on $\alpha$-nuclide distribution images in fish body are few.

This paper describes the methods to obtain the images of $\alpha$-emitter in fish body with nuclear track detector CR-39 and to obtain the radioactivity density of inner organ of fish.

\footnotetext{
*Corresponding author. Email: moric@wh.commufa.jp
}

\section{Some images of alpha emitter distribution}

\subsection{Alpha particle distribution image emitted from the inner organ of sardine}

Since CR-39 is insensitive to $\beta$ - and $\gamma$-rays, radiation shielding box is not needed at the exposure. The plate of CR-39 is inexpensive and any expensive instruments are not required. Even if radioactivity density in the specimens such as environmental natural materials is very low, long term exposure of the specimens on CR-39 enables us to obtain the images.

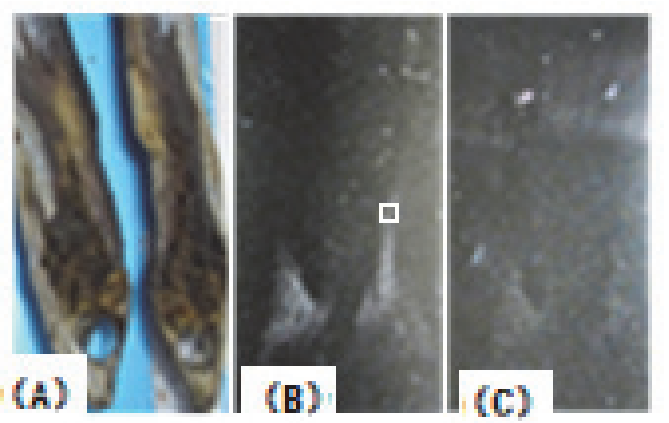

Figure 1. (A) Dried sardines, (B) $\alpha$-particle pits obtained by 89days exposure on CR-39, (C) obtained by 2 nd exposure 85 days after one year.

Figure 1 (A) shows the flat surfaces of dried sardine obtained by cutting with a knife, (B) $\alpha$-particle emission image of them obtained with 1 st exposure for 89 days on CR-39 and chemical etching with sodium hydroxide of $7.5 \mathrm{~N}, 80^{\circ} \mathrm{C}$, for 5 hours and (C) the image obtained with 
the 2nd exposure for 85 days after one year of the 1 st exposure. The ratio of the pit density of the 2 nd exposure to that of the 1st exposure at the same place of the sardine was about $0.25 \pm 30 \%$. When ${ }^{210} \mathrm{Po}$ was in radioactive equilibrium with ${ }^{210} \mathrm{~Pb}$, this ratio should be unity. And when only ${ }^{210} \mathrm{Po}$ with the half-life of 138.4 days was present, the ratio should be 0.16 . By taking account of the ratios 0.25 and $0.16,{ }^{210} \mathrm{Po}$ seemed not to be fully in the radioactive equilibrium with ${ }^{210} \mathrm{~Pb}$, although the ratio 0.25 contained large error.

\subsection{Some other images including each inner organ}

Figure 2 (A) shows dried fresh-water fish: pond smelt (left) and sweet fish (right) and (B) their $\alpha$-particle images in which noticeable etch pits were not seen, because the concentration of uranium in Japanese river is small $\sim 0.041 \mu \mathrm{g} / \mathrm{L}$ compared with that $\sim 3.3 \mu \mathrm{g} / \mathrm{L}$ in sea water.

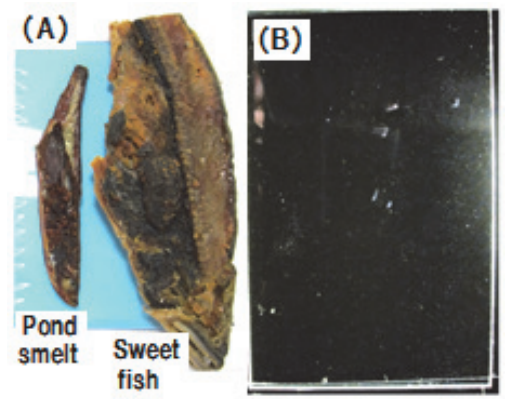

Figure 2. Fresh water fish: (A) pond smelt and sweet fish, (B) $\alpha$-particle image.

Figure 3 shows (a) golden threadfin bream, (b) each inner organ taken out, (c) dried each organ, and (d) each pit image.

\section{Determination of radioactivity density and absorption dose}

\subsection{Calculation of detection efficiency of a-particles emitted in inner organ}

To obtain the $\alpha$-radioactivity density contained in the inner organ of fish from the pit density on the surface of CR-39, it is necessary to find the detection efficiency of $\alpha$-particles emitted in the inner organ. Here it is supposed that ${ }^{210} \mathrm{Po}$ is uniformly distributed throughout the related inner organ.

Figure 4 (a) shows explanatory drawing. The bulk etching thickness was $15.9 \mu \mathrm{m}$ which was deleted layer by the chemical etching. Alpha-particle emitted at the depth $t_{i}$ in inner organ with an angle $\theta_{i}$ loses its initial energy $E_{0}(5.3 \mathrm{MeV})$ through the length $L_{i}$ in inner organ and then through $L_{c}$ in CR-39. The particle with energy $E_{b}$ enters into the surface which will appear as a pit after chemical etching. Energy $E$ and energy loss $(-d E / d x)$ were calculated by Eq. (1).

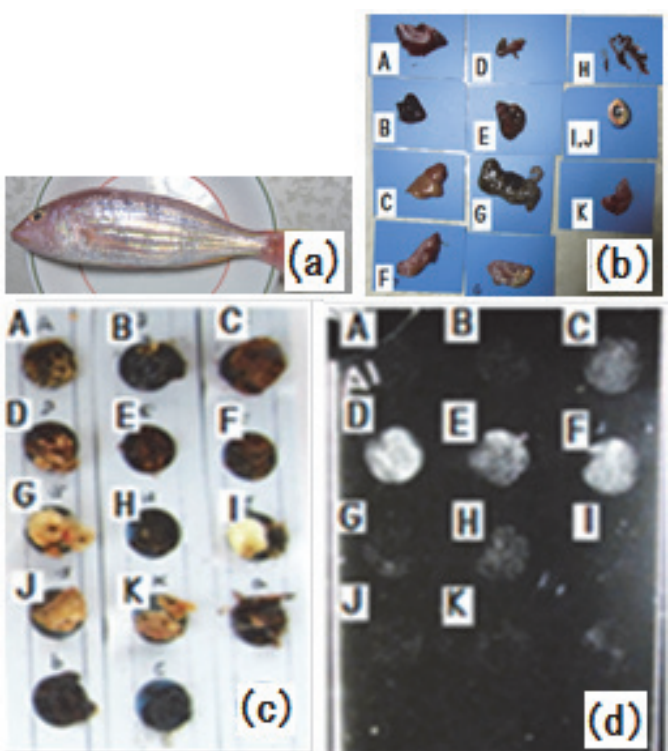

Figure 3. (a) golden threadfin bream, (b) each inner organ, A: gills, B: heart, C: liver, D: gallbladder?, E: pancreas, F: stomach, G: pylorus, H: spinal cord, I and J: eye ball and palpebral, K: spleen?, (c) dried each organ, (d) pit image of each organ obtained with exposure for 85 days.

$$
\begin{gathered}
E_{b}=E_{0}-\int_{0}^{L_{i}}\left(-\frac{d E}{d x}\right)_{i} d x-\int_{L_{i}}^{L_{i}+L_{c}}\left(-\frac{d E}{d x}\right)_{c} d x \\
\text { where } L_{i}=\frac{t_{i}}{\cos \theta_{i}} \quad \text { and } L_{c}=\frac{15.9 \mu m}{\cos \theta_{i}}
\end{gathered}
$$

$(-d E / d x)_{i}$ and $(-d E / d x)_{c}$ are the energy losses in inner organ and in CR-39, respectively, which were calculated by Bethe formula [10]. The validity to use Bethe formula was confirmed in the reference [11]. When $E_{b}$ equals $0.2 \mathrm{MeV}$, it was considered that the particle was not able to make an observable pit on the surface of CR-39, because the penetration range was only $1.4 \mu \mathrm{m}$.

By changing the angle $\theta_{i}$ in the calculation with Eq. (1), it is easy to obtain $E_{b}=0.2 \mathrm{MeV}$. The angle $\theta_{i}$ at that case is the maximum detectable angle for $\alpha$-particle emitted at the depth $t_{i}$ in inner organ. The detection efficiency $\eta_{i}$ is obtained by Eq. (2).

$$
\eta_{i}=\left(1-\cos \theta_{i}\right) / 2
$$

The atomic composition of CR-39 is $\mathrm{H}: 17, \mathrm{C}: 12$, O:7 and the density is 1.31 . The composition and the density 1.05 of the inner organ of fish were considered to be the same to human body as shown in Table 110 in ICRP Publication [12]. However, in the calculation, the density of dried fish was estimated to be the same to that of raw fish by the rough measurements of weight and the geometrical volume size. It was also considered that there was no elemental composition change between the dried fish and raw fish, although this is rather rough consideration. Figure 4 (b) shows an example of the energy $E$ and the energy loss $(-d E / d x)$ of $\alpha$-particle (5.3 $\mathrm{MeV}$ ) emitted from ${ }^{210} \mathrm{Po}$ at the depth $t_{i}=16 \mu \mathrm{m}$ with the angle $\theta_{i}=29$ degree. 

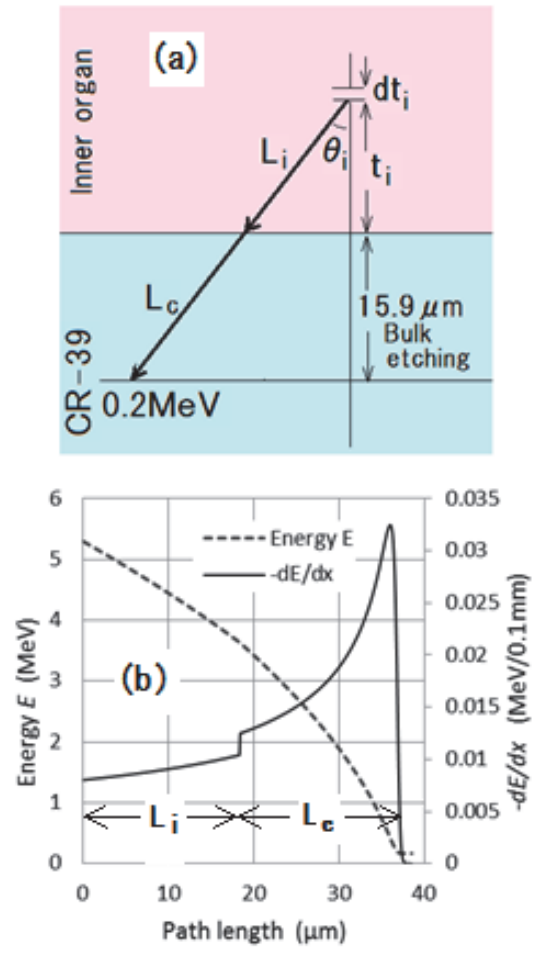

Figure 4. (a) Explanatory picture to calculate detection efficiency of alpha particles emitted in inner organ. The thickness $15.9 \mu \mathrm{m}$ was a deleted thickness, called bulk etching, of CR-39 by chemical etching. (b) Energy loss $(-d E / d x)$ and energy $E$ calculated by Bethe formula.

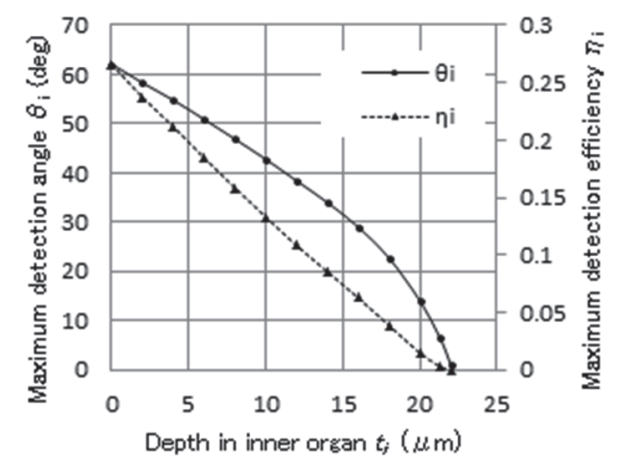

Figure 5. Maximum detection angle $\theta_{i}$ and maximum detection efficiency $\eta_{i}$ for $\alpha$-particle emitted at depth $t_{i}$ in inner organ.

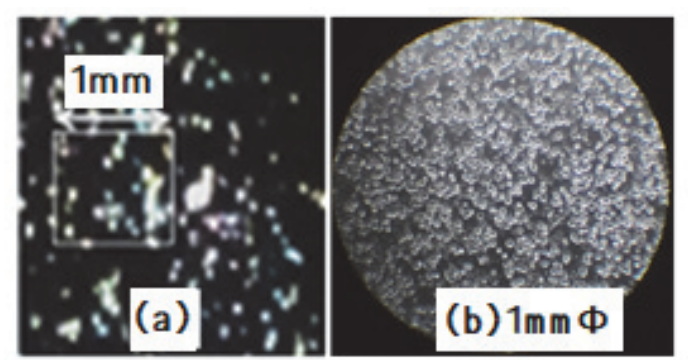

Figure 6. (a) Pit density $27( \pm 20 \%) / \mathrm{mm}^{2}$ of inner organ of sardine in a small white square shown in Figure 1 (B), and (b) the density $1637 / \mathrm{mm}^{2}$ of the liver $\mathrm{C}$ in Figure 3 (d) of golden threadfin bream.
Figure 5 shows maximum detection angle $\theta_{i}$ obtained by the calculation with Eq. (1) and maximum detection efficiency $\eta_{i}$ obtained by Eq. (2).

From Eq. (1), it is possible to obtain the maximum depth $t_{\text {imax }}$ to be $22 \mu \mathrm{m}$ by putting $\theta_{i}=0$. Therefore, the total detection efficiency $\eta$ for $\alpha$-particles emitted in the thickness range from $t_{i}=0$ to $t_{\text {imax }}$ is obtained by Eq. (3).

$$
\eta=\frac{1}{t_{\text {imax }}} \int_{0}^{t_{i \max }} \eta_{i} d t_{i}
$$

The total detection efficiency $\eta$ was 0.12 . This value depends on the material of the specimen. It is about 0.12 for organic material as mentioned above and about 0.14 for stones etc. To obtain the radioactivity density, it is necessary to know the value of $t_{\text {imax }}$ which is about $22 \mu \mathrm{m}$ for organic material and around $10 \sim 15 \mu \mathrm{m}$ for stones.

\subsection{Radioactivity density and absorbed dose in the inner organ of fish}

When the radioactivity density is $A\left[\mathrm{~Bq} / \mathrm{cm}^{3}\right]$ in the inner organ of fish and the maximum detection depth is $t_{\text {imax }}[\mathrm{cm}]\left(=2.2 \times 10^{-3} \mathrm{~cm}\right)$, pit density $n\left[\mathrm{~cm}^{-2}\right]$ produced in 1 second is equal to $A\left[\mathrm{~Bq} / \mathrm{cm}^{3}\right] \times \eta \times t_{\text {imax }}[\mathrm{cm}]$. From the pit density $N$ [pits $/ \mathrm{cm}^{2}$ ] obtained by the image through $M$ day exposure, the radioactivity $A\left[\mathrm{~Bq} / \mathrm{cm}^{3}\right]$ is expressed by Eq. (4).

$$
A\left[\mathrm{~Bq} / \mathrm{cm}^{3}\right]=\frac{N\left[\mathrm{pits} / \mathrm{cm}^{2}\right]}{M[\text { days }]} \times 4.4 \times 10^{-2}
$$

Figure 6 (a) shows the pit image of the small white squared area of sardine shown in Figure 1 (B) obtained by 89 day exposure. The pit density was $27( \pm 20 \%)$ per $\mathrm{mm}^{2}$, then $N=27 \times 10^{2} \mathrm{~cm}^{-2}$ and the radioactivity density $A$ was $1.3 \mathrm{~Bq} / \mathrm{cm}^{3}$.

When a sardine is alive, it is considered that the radioactivity density in the inner organ is constant for a year through the process of the ingestion-intake, discharge and decay with the half-life of radioactivity. The absorbed dose by $\alpha$-particles $(5.30 \mathrm{MeV})$ from ${ }^{210} \mathrm{Po}$ was $33 \mathrm{mGy} / \mathrm{y}$ when the mass density is 1.05 . If the radiation quality factor (20 for alpha-particle) can be applicable to fish inner organs as same to the human body, the equivalent dose of fish inner organs is 660 $\mathrm{mSv} / \mathrm{y}$.

In the case of the liver ( $\mathrm{C}$ in Figure $3(\mathrm{~d})$ ) of golden threadfin bream, pit density was $1,637 \mathrm{pits} / \mathrm{mm}^{2}$ (Figure $6(\mathrm{~d}))$ and the radioactivity was $85 \mathrm{~Bq} / \mathrm{cm}^{3}$, the absorbed dose was $2.2 \mathrm{~Gy} / \mathrm{y}$ and the equivalent dose was about 44 $\mathrm{Sv} / \mathrm{y}$ when the radiation quality factor 20 was applied.

Figure 3 (d) shows that the pit density and hence radiation absorbed dose largely depend on each inner organ of fish.

\section{Conclusion}

The itemized conclusions are as follows.

1) The images of $\alpha$-particle emission from the inner 
organ of fish were obtained with CR-39.

2) The decrease of the etch pit density after one year showed that ${ }^{210} \mathrm{Po}$ was not fully in radioactive equilibrium with ${ }^{210} \mathrm{~Pb}$.

3) Fresh-water fish seemed not to contain $\alpha$-emitters.

4) Detection efficiency of $\alpha$-particle emitted in inner organ of fish with CR-39 was theoretically obtained and it was 0.12 .

5) Absorbed dose of a part of the inner organ of a sardine was $33 \mathrm{mGy} / \mathrm{y}$.

6) Absorbed dose of the liver of a golden thread bream was $2.2 \mathrm{~Gy} / \mathrm{y}$.

7) Since CR-39 method is very simple and inexpensive compared with chemical analytical method, anyone is able to obtain the image and measure the radioactivity of $\alpha$-emitters in fish or in other material, although it needs a few month exposure.

\section{Acknowledgements}

The author would like to express his thanks to Professor Emeritus Takao Iida, Professor Hiromi Yamazawa, and Associate Professor Jun Moriizumi of Nagoya University.

\section{References}

[1] Radiations in Living Environment, New Edition, Nuclear Safety Research Association (2011, Dec.), p. 50. [in Japanese]

[2] A.J. Pearson, S. Gaw, N. Hermanspahm and C.N. Glover, Activity concentrations of ${ }^{137}$ Caesium and ${ }^{210}$ Polonium in sea food from fishing regions of New Zealand and the dose assessment for seafood consumers, J. Environmental Radioactivity, 151 (2016), pp. 542-550.

[3] L. Alam and C.A.R. Mohamed, A mini review on bioaccumulation of ${ }^{210} \mathrm{Po}$ by marine organisms, International Food Research Journal, 18 (2011), pp. 1-10.

[4] F.P. Carvalho and S.W. Fowler, An experimental study on the bioaccumulation and turnover of polonium-210 and lead-210 in marine shrimp, Marine Ecology Progress Series, 102 (1993), pp. 125-133.

[5] A. Aarkrog, M.S. Baxter, A.O. Bettencourt, R. Bojanowsky, et al., A comparison of doses from ${ }^{137} \mathrm{Cs}$ and ${ }^{210} \mathrm{Po}$ in marine food: a major international study, J. Environmental Radioactivity, 34 (1997), pp. 69-90.

[6] Y. Takizawa, Polonium in Human Body, anshin-kagaku_news.coocan.jp/Po210takizawa072 9.pdf (2017/04/04). [In Japanese]

[7] UNSCEAR2000, United Nations, 1 (2000), pp. 125-130.

[8] T. Miura, K. Hayano and K. Nakayama, Determination of ${ }^{210} \mathrm{~Pb}$ and ${ }^{210} \mathrm{Po}$ in environmental samples by alpha ray spectroscopy using an extraction, Analytical Sciences, 15 (1999), pp. 23-28.

[9] A. Lubna, N.A. Nik Azlin, S. Afiza Suriani and C.A.R. Mohamed, A study on the activity concentration of Po-210 in the marine environment, J. of Tropical Marine Ecosystem, 1 (2011), pp. 1-8.

[10]N. Tsoulfanidis, Measurement and Detection of Radiation, Hemisphere Publication Corporation (1983), p. 118.

[11]C. Mori, Macro-autoradiographs of alpha emitters in environmental materials observed with solid-state track detector CR-39, J. Nucl. Sci. Technol. 50 (2013), pp. 891-897.

[12]ICRP Publication 23, Reference man Data (1975), p. 327. 